\title{
Simulation of Grid-Tied Photovoltaic System Based on Solar Irradiance and Temperature Data in Semarang.
}

\author{
Ahmed Jumui Sumoi Fomba ${ }^{1,}$, , Hermawan Hermawan ${ }^{2}$, Trias Andromeda ${ }^{2}$, Mochammad Facta ${ }^{2}$, and Iwan Setiawan ${ }^{2}$ \\ ${ }^{1}$ Magister Study Program of Electrical Engineering, Diponegoro University, Semarang - Indonesia \\ ${ }^{2}$ Department of Electrical Engineering, Faculty of Engineering, Diponegoro University, Semarang - Indonesia
}

\begin{abstract}
This paper presents a simulation of a grid-connected photovoltaic power system. A complex model of power distribution system is developed in MATLAB Simulink, then it will be simulated to determine an amount of power delivered to the grid based on irradiance and temperature. Solar irradiance data collection is conducted using a solar irradiance meter. These weather data (solar irradiances and temperatures) are transformed into signal inputs and model through a grid-tied Photovoltaic (PV) model system which consists of PV, incremental conductance Maximum Power Point Tracking (MPPT) method, DC-DC boost converter, inverter, voltage source converter (VSC) control algorithms, and grid equipment. The output variables can be related to current, voltage or power. However, tracing of the current-voltage $(\mathrm{I}-\mathrm{V})$ characteristics or power-voltage $(\mathrm{P}-\mathrm{V})$ characteristics are the vital need to grid-tied PV system operation. Changes in solar irradiance and temperature imply changes in output variables. Detailed modelling of the effect of irradiance and temperature, on the parameters of the PV module and the output parameters will be discussed. With the aid of this model, one can have a feasible idea about the solar energy generation potential at given locations. This comprehensive model is simulated using MATLAB/Simulink software.
\end{abstract}

Keywords: Grid-Integration; Photovoltaic Array; MPPT; Boost-Converter; Inverter.

\section{Introduction}

The grid interconnection systems bring a new phase to the renewable power technology via showcasing the time-based excess and limitations with renewable power generation to the conventional grid model; that generates base-load power [1]. Several issues with conventional generation productions have influenced the need for the advancement of photovoltaic systems utilization. Some of these factors are: the global demand for electricity is ever-growing and the conventional means of generating electricity cannot solely meet this rising challenge. It is evidently clearer that the operation of conventional engines come with some huge costs like high operation and maintenance cost, rapid changing in generator consumables price, unavailability of diesel fuel in some cases, emission of greenhouse gases (GHG) into the atmosphere. These among other issues have influenced the need for sustainable and environmental friendly solutions. Another important issue is the fact that photovoltaic technology is continuously evolving to becoming better and the price per kilowatt is relative cheaper today [2].

However, photovoltaic technology also has its limitations as well, due to its planned outage associated with night time, as a result of the unavailability of solar irradiance [3]. The undetermined occurrences of passing clouds or change in temperature do affect system reliability or trigger equipment failure, and likely to cause a forced outage in the system [4]. The need for a forced outage in the system is an excellent indicator of system problems and/or equipment failures that are revealed in lessened plant output production and capacity factor. Likewise, disturbances due to delay in passing clouds could also momentarily change the voltage delivered by the photovoltaic generating modules. The voltage source controller of the inverters linking the DC end of photovoltaic modules to the gridtied system, do experience constraint in handling such changes. Subsequently, this may lead to a fail operation and trigger a force shutdown of the inverter [5].

It is obviously clear that; both systems (photovoltaic and conventional means) of energy generations do have limitations but there are existing capabilities to have a synchronous operation of generating electricity and complement each other. However, there are some drawbacks associated with this means and also improvements been made to overcome some of these drawbacks [2]. As the need for the use PV grid-tied system becomes feasible; the efficiency, performance and reliability concerns are becoming more vital for the emerging photovoltaic markets $[6,7]$. The purpose of the study is to evaluate the model performances of varying solar irradiances and temperature on PV module, P-V characteristics and its effect on the output power to the grid.

\footnotetext{
* Corresponding author: ahmedfomba84@gmail.com; hermawan.60@gmail.com
} 


\section{Theoretical Background}

\subsection{Solar Irradiance}

Solar irradiance can be described as the sun radiant power penetration per unit area upon the surface. It has a unit of watt $/$ meter $^{2}$. Sun rays consist of electromagnetic waves that are composed of various energy levels of photons that move at a constant velocity. The radiant power can be defined as the flow rate of electromagnetic energy. Solar radiation has typical wave like features, with its wavelength $(\lambda)$ inversely proportional to its photon energy (E).

$$
E=\operatorname{ch} / \lambda
$$

where:

$c=$ as the speed of light,

$h=$ is the equivalent Planck's constant [4]

Table 1. Weather report as at data collection period [8]

\begin{tabular}{|l|l|}
\hline Date & Saturday, 4 May 2019 \\
\hline Time & $07: 00-13: 00$ \\
\hline Temperature & $25 / 34^{\circ} \mathrm{C}$ (lowest/highest respectively) \\
\hline Humidity & $86 / 56 \%$ \\
\hline Barometer & $1012 / 1009 \mathrm{mbar}$ \\
\hline Wind Speed & $6 / 13 \mathrm{~km} / \mathrm{h}$ \\
\hline Source & Courtesy of www.timeanddate.com \\
\hline
\end{tabular}

\subsection{Modeling of Photovoltaic Module}

There are numbers of equivalent circuit models [9] of solar cell available in literature but this paper focuses on Single-diode model for simplicity and accuracy[10, 11]. A Single-diode solar cell equivalent circuit is outlined in Fig. 1.

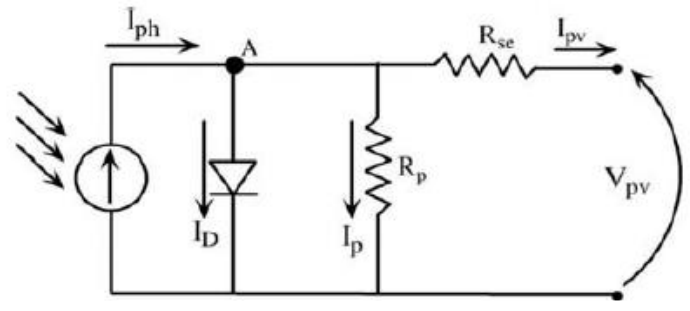

Fig. 1. Equivalent circuit of single diode model 11.

Applying Kirchhoff's current law at node ' $A$ ' in Fig. 1:

$$
I_{\mathrm{pD}}=I_{\mathrm{ph}}-I_{D}-I_{\mathrm{p}}
$$

where:

$I p v$ is denoted as the output current of photovoltaic $I p h$ is denoted as the photocurrent

$I p$ is denoted as the current passing through parallel resistance and $I_{D}$ is denoted as the current passing through the diode, and also represented by the principle of Semiconductor equation as follows [11].

$$
I_{D}=I_{O}\left[\exp \left(\frac{q\left(V_{p D}+I_{p V} R_{g}\right)}{A N_{g} K T}\right)-1\right]
$$

Io denoted as reverse saturation current of the diode. $V p v$ denoted as the photovoltaic output voltage. $N s$ is denoted as a sum of photovoltaic cells connected in series, $A$ denoted as ideality factor and is based on photovoltaic cell manufacturer, $K$ denoted as Boltzmann constant $(1.38 \times 10-23 \mathrm{~J} / \mathrm{K})$ and $T$ denoted as the temperature of the cell. The resolved output current of PV model for the circuit in Fig. 1 is outlined as [11]:

$I_{p D}=I_{p h}-I_{0}\left[\exp \left(\frac{q\left(V_{p D}+I_{p V} R_{g}\right)}{A N_{g} K T}\right)-1\right]-\frac{V_{p D}+R_{\alpha}\left(44_{D}\right.}{\left.R_{p}\right)}$

The five main parameters in the defining equations of solar cell are ideality factor, saturation current, photocurrent, series, and parallel resistances. These parameters are affected by the solar cells immediate temperature and solar irradiance. The following experimental data are usually provided by manufacturers namely: open circuit voltage, short circuit current, and voltage at the maximum power point, current at maximum power; are normally given at standard testing conditions. The practical working environments of solar cells vary from the standard testing conditions. The defining of these variables play a significant role in the formation of the photovoltaic module.

\subsection{The Impact of Temperature and Solar Intensity on Photovoltaic System}

Two major features that help determine the output of photovoltaic system are namely: solar irradiance and temperature [7]. An increase in solar cell temperature corresponds to an increase in energy loss in the photovoltaic module or the solar intensity. The photovoltaic module does experience a decline in its output power as a result of rising temperature index during operation. Therefore, an increase in solar cell temperature leads to the corresponding decline in the open circuit voltage of the PV module. Hence, the output current of the PV module does experience a rise in index value corresponding to the cell temperature. Evidently, the temperature and solar irradiance do change the values of photovoltaic module output voltage and current. Therefore, the impact of the temperature and solar irradiance on photovoltaic system modeling must be determined. The characteristic of an anticipated photovoltaic module is attained by the current-voltage rendition method as follows in the equations [11].

$$
I_{\text {se }}=I_{\text {seref }}\left[1+\alpha\left(T-T_{\text {ref }}\right)\right] \frac{G}{G_{\text {ref }}}
$$

$V_{o c}=V_{\text {oc ref }}\left[1+a \ln \frac{G}{G_{\text {ref }}}+\beta\left(T-T_{\text {ref }}\right)\right]$

Where $\alpha$ and $\beta$ are related to coefficients of temperature. $G$ and $G_{r e f}$ are equivalent of the solar 
irradiances at operating and reference conditions respectively. $T$ and $T_{r e f}$ are the temperatures of the solar cell at operating and reference values and $a=$ the solar irradiance correction factor.

\subsection{Maximum Power Point Tracking (MPPT) Algorithms}

The major weather parameter input (temperature and solar irradiance) of PV module keeping varying during operation. To determine the MPP of operation of a photovoltaic module, during operation as the weather parameters vary. A MPPT technique is needed to determine and sustain the peak power at every instance of variation. This approach targets to find the voltage or current under which the photovoltaic module provides the maximum output power. The MPPT procedures are designed based on different features like strategic control, variables control algorithm, robust circuitry performance, costs [11-13]. There are several MPPT algorithms but this simulation focuses on the incremental conductance method.

\subsection{DC-DC Boost Converter}

The DC-DC boost converter is used to maximize the photovoltaic array output voltage to an acceptable system voltage of the inverter. This converter integrates the PV output to the inverter and helps determine the MPP on the current-voltage curve with the support of the control algorithm (MPPT). The output voltage wave form is then filtered by the capacitor and inductor, in order to cut off unwanted frequency signals. The switched mode of DC-DC converters usually consists of power switch with capacitor and inductor. ' $V o$ ' is denoted as the output voltage of the boost converter and normally has an outlined expression as: [14]

$V_{0}=\frac{V_{s}}{1-D}$

where:

$D=$ duty cycle

$V_{s}=$ source voltage

\subsection{Inverter}

The operation of an inverter is based on modulation schemes, thereby triggering the inverter output to vary between positive and negative direct current voltage values. Its switches are operated at a time base interval to obtain an average value of its output, which is similar to an equivalent alternating current sine wave form. Its outputs are filtered by capacitors and inductors to diminish unwanted frequency content and attain pure sine wave form. [15].

\subsection{Controller}

In the case of power system design, having 3-phase termination to the grid, numerous control tactics have been designed to lessen voltage fluctuation and unbalance voltage effect in power systems [16-19]. A well-designed control algorithm can be applied to the inverter to quell the fluctuations in voltage, based on the voltage vector technique at the inverter terminal and reference vector, an error is generated. This difference in error is feedback into the controller, with the aim to alter the reference voltage value immediately, in order to lessen fluctuation of voltage and voltage imbalance in the system. A series of variable structured, predictive and sliding mode control, are used. This structured result is considered to be complex but also robust and effective $[19,20]$.

\subsection{Grid}

A load of the grid-tied photovoltaic inverter(s) in an electric utility is the network. Normally, the electric utilities defined the operational settings for the grid connected photovoltaic system and these settings usually vary from one electric utility to another. To overcome some the challenges associated with power system operation, generating modules must be capable to withstand set points of fault interferences in the grid connected system and support the voltage by injecting reactive power compensator. This method is called faultride-through (FRT) [21]. Subsequently, the regulation of active power is essential to control the irregular frequency situation. High penetration of grid connected photovoltaic (GCPV) requires involvement of robust control to attain grid stability. Among other methods required to maintain the grid stability are static grid support by reactive power control, active power control and dynamic power supports.

\section{Simulation, Results, and Analysis}

\subsection{Simulation}

This simulation study was intended to measure the behavior and performance of a grid connected photovoltaic system under real time solar irradiance and temperature data. The solar irradiance data collected by the use of solar power meter at an interval of one second and temperature data obtained from the timeanddate.com site.

These weather data were transformed to signals and served as input to the grid-connected photovoltaic model. The photovoltaic array delivers active power to the boost converter in alignment with the MPPT algorithm. The output voltage from the PV array is been boosted via DC-DC converter in order to attain the required inverter input voltage. The VSC control system regulates the outer loop control which regulates the direct current link voltage and the inner loop control together with the reactive and active power designations. A three-phase level bridge inverter is utilized to convert direct current power to $50 \mathrm{~Hz}$ AC output power. A $12 \mathrm{KVAR}$ capacitor bank is connected to the output side of the inverter which served as a reactive power compensator in the model. This AC output power goes 
through a step-up transformer and then to the grid. The simulation was carried out using the MATLAB/Simulink.

Table 2. Basic Simulation parameters for proposed system

\begin{tabular}{|l|l|}
\hline Parameter & Value \\
\hline PV array (5*80) & $400 \mathrm{~W}$ \\
\hline Boost Converter frequency & $5 \mathrm{KHz}$ \\
\hline DC link Capacitors(2) & Cdc $12000 \mu \mathrm{F}$ \\
\hline Ts Conttrol & $12000 \mu \mathrm{s}$ \\
\hline Ts Power & $1 \mu \mathrm{s}$ \\
\hline Descrete Time & $1 \mu \mathrm{s}$ \\
\hline DC reference voltage & $500 \mathrm{~V}$ \\
\hline 3 level 3-phase VSC & $1650 \mathrm{~Hz}$ \\
\hline 3 Level bridge Inverter & $3 \mathrm{arms}$ \\
\hline PV to Grid Transformer(Step Up) & $100 \mathrm{KVA}(260 \mathrm{~V} / 25 \mathrm{KV})$ \\
\hline Capacitive Reactive Power & $12 \mathrm{KVAR}$ \\
\hline Line inductance, & $0.25 \mathrm{mH}$ \\
\hline Line resistance, & $1,885 \mathrm{mOhms}$ \\
\hline
\end{tabular}

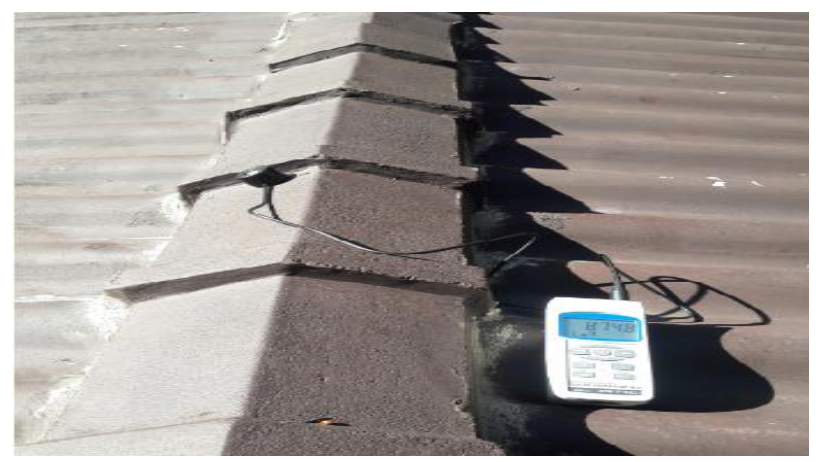

Fig. 2. Solar irradiance data being recorded at time interval of one second.

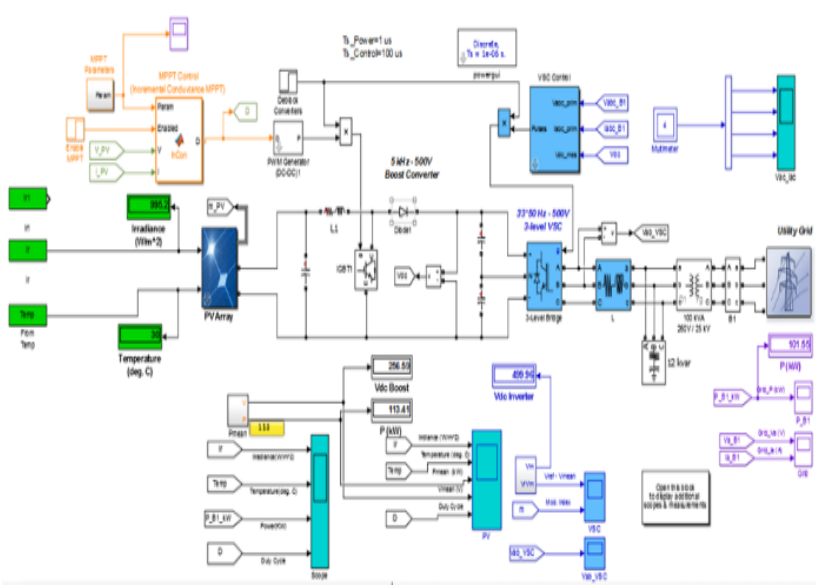

Fig. 3. An outlined diagram of a grid-tied PV array model

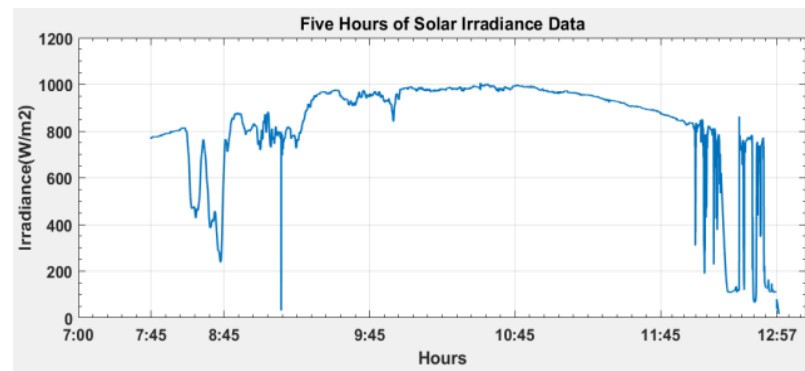

Fig. 4. Active hours of data collection, shows solar irradiance output waveform at Semarang. Started recording data at 7:45hrs and ended at 12:57hrs

\subsection{Results}

The results of the simulation model are presented below. Detailed of discussion of results are presented in subsection analysis.

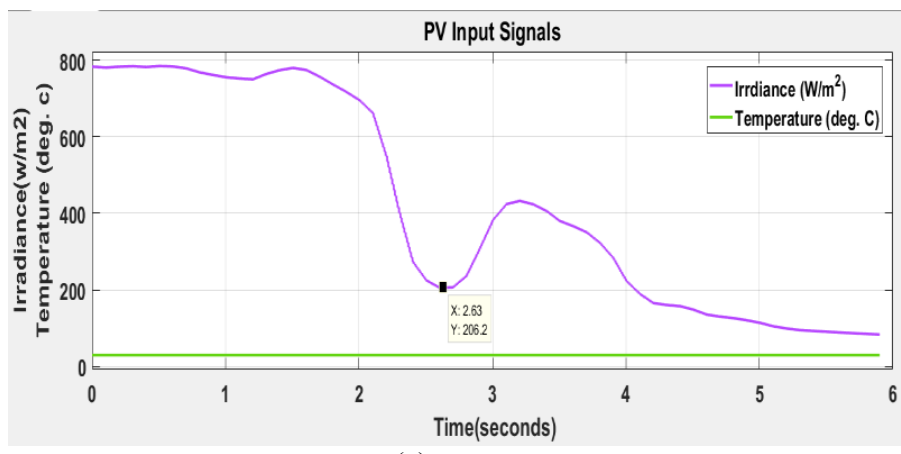

(a)

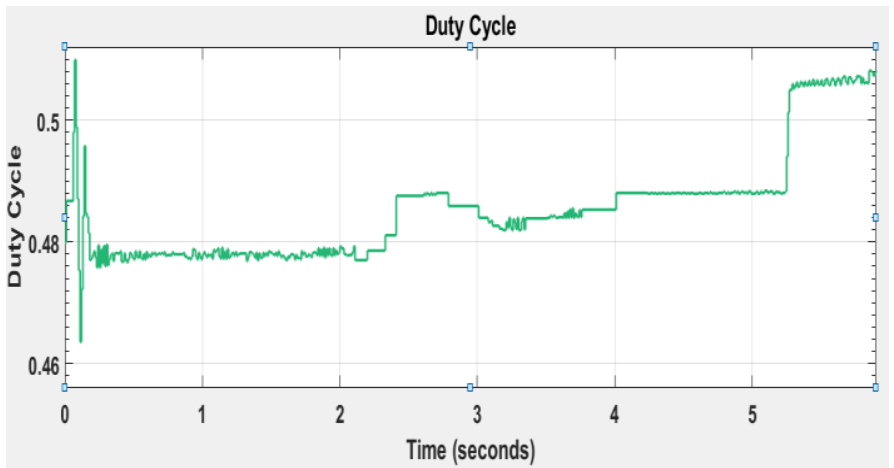

(b)

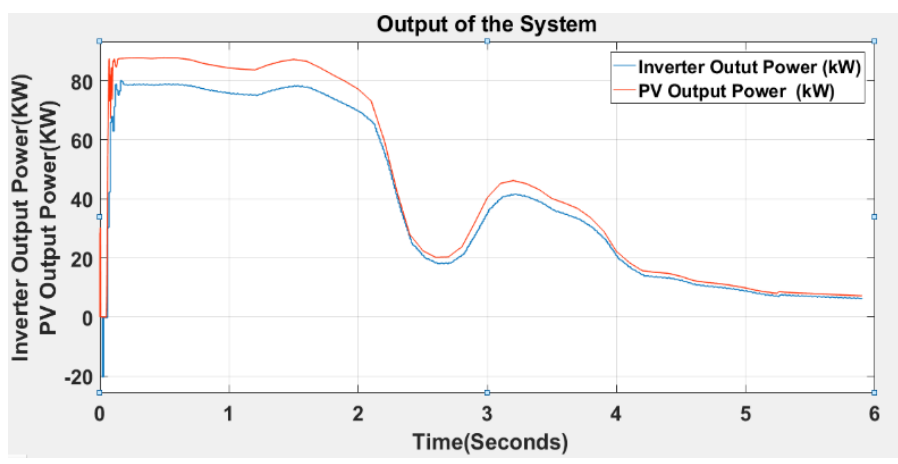

(c)

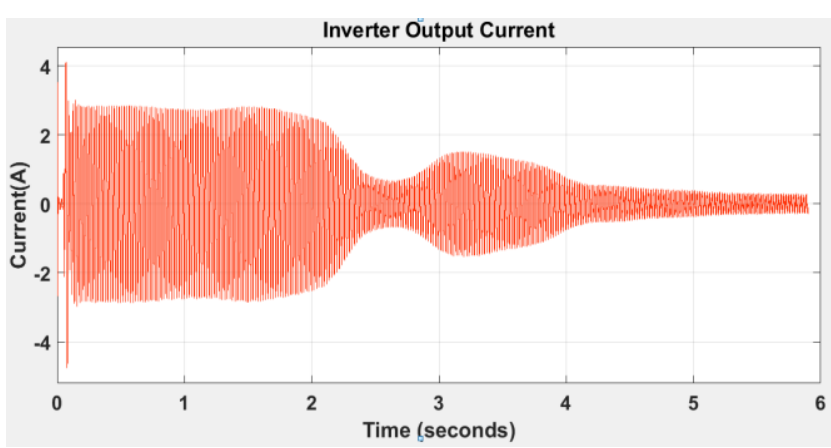

(d)

Fig. 5. Solar Irradiance cloud data waveform (a) PV input signals, (b) duty cycle, (c). PV and inverter output power and (d) inverter output current. 


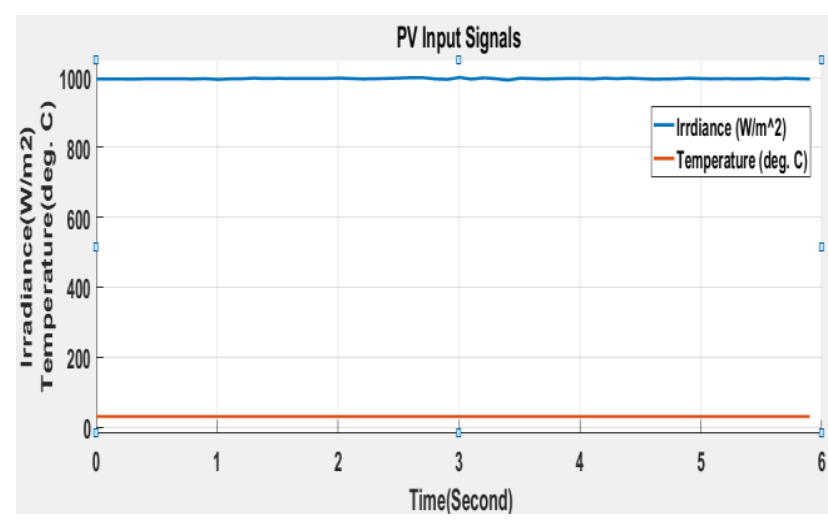

(a)

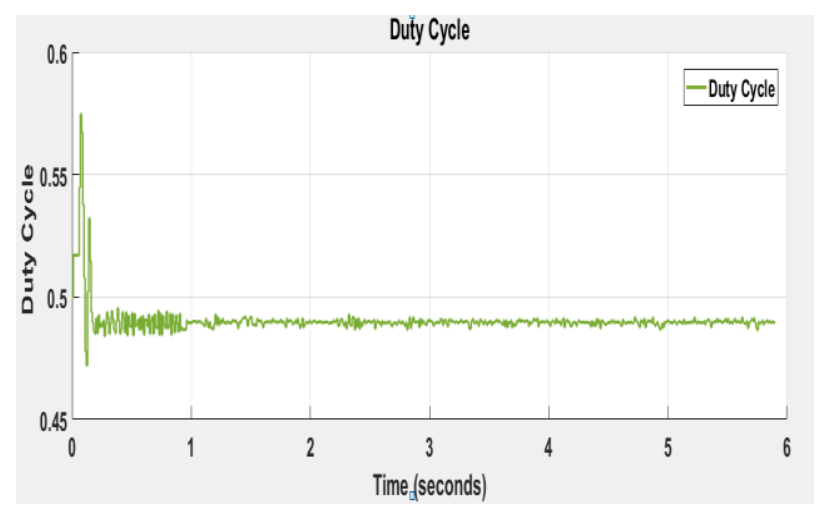

(b)

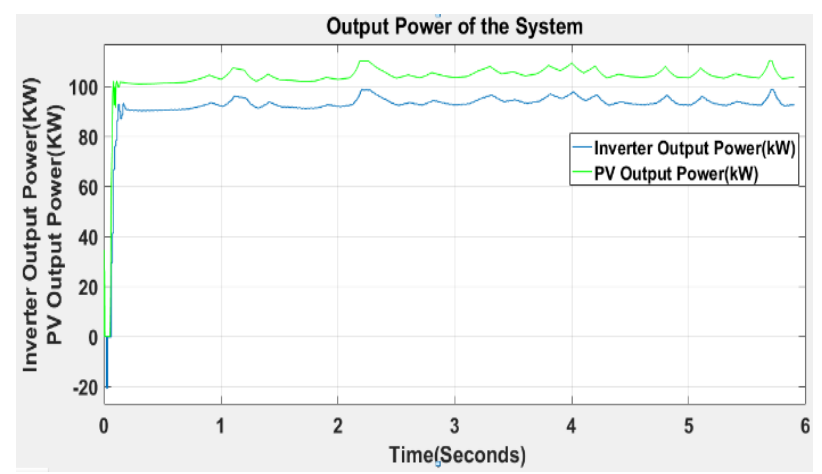

(c)

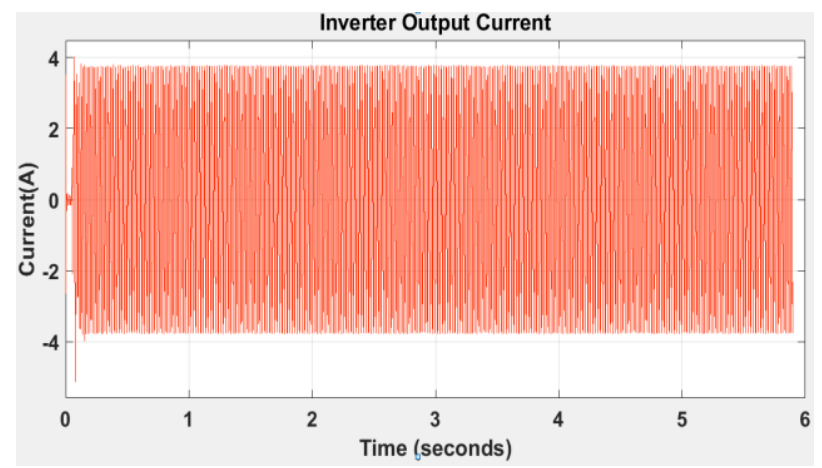

(d)

Fig. 6. Peak Solar irradiance data with moderate deviation range (a) PV input signals (b) duty cycle (c). PV and inverter output Power (d) inverter output current.

\subsection{Analysis}

With reference to Fig. 5, the simulation modeling started at the time $(\mathrm{t})=0$ second with $784.5 \mathrm{~W} / \mathrm{m}^{2}$ irradiance, in relation to the scope readings in Fig. 5(a) and an average constant temperature of $30^{\circ} \mathrm{C}$ was determined. In Fig. 5 (a), at $\mathrm{t}=2$ seconds the model experienced considerable drop in irradiance from $695.1 \mathrm{~W} / \mathrm{m}^{2}$ to $206.5 \mathrm{~W} / \mathrm{m} 2$ at $\mathrm{t}=$ 2.66 seconds. The effect of this sharp declined in irradiance value can be spotted at the PV output power in Fig. 5(c). At $\mathrm{t}=2$ seconds, the PV power output was 87.86.KW and at $\mathrm{t}=2.66$ seconds, the PV output power was reduced to $20.31 \mathrm{KW}$. Also in Fig. 5(c), the inverter output power to the grid at $\mathrm{t}=2$ second was $70 \mathrm{KW}$ and at $\mathrm{t}=2.66$, it was at recorded as $18.11 \mathrm{KW}$. As the irradiance continues to fluctuate and finally reached a record low of $83.7 \mathrm{~W} / \mathrm{m}^{2}$ at $\mathrm{t}=5.9$ seconds. This effect fluctuation was also noted on the inverter output current to the grid in Figure 5(d) and the output power of the system in Figure 5(c), which were recorded as $7.20 \mathrm{KW}$ for the PV output power and $6.40 \mathrm{KW}$ for the inverter output power. In Fig. 5(b), an unstable performance was recorded on the duty cycle at $\mathrm{t}=2.1$ seconds which corresponded to $669.5 \mathrm{~W} / \mathrm{m}^{2}$, as the value of the irradiance continued to decrease rapidly to $207.7 \mathrm{~W} / \mathrm{m}^{2}$, a steeped rise was noted in the MPPT duty cycle at $t=$ 2.41 seconds. This same behavior was noted again at $\mathrm{t}=$ 5.41 second on the duty cycle when the irradiance further declined to $98 \mathrm{~W} / \mathrm{m}^{2}$. It can be observed that the duty cycle attained its highest value (0.57) in operation when the irradiance was at its lowest $\left(83.7 \mathrm{~W} / \mathrm{m}^{2}\right)$ value. In Fig. 5(d) an unstable oscillation of grid current was noted at $\mathrm{t}=2$ second and then throughout the cloud sampling time simulated. Unlike the duty cycle waveform in Fig. 5(b); Fig. 6(b) recorded stable output waveform at $\mathrm{t}=0.1$ second and the duty cycle output was generally stable for the remaining seconds of this peak sample data.

Relating to Fig. 6, there were moderate deviations recorded in this sample (the least irradiance value at that time interval was $994.3 \mathrm{~W} / \mathrm{m}^{2}$ ) with reference to temperature and irradiance values in Fig. 6(a). The disturbances noted in Fig. 6 were at the starting time at $t$ $=0 \mathrm{sec}$ in relation to scope data. The system was stabilized at $\mathrm{t}=0.1$ second in Figure $6(\mathrm{~b})$ with the techniques of the MPPT. At time $\mathrm{t}=3$ seconds, peak irradiance value of $1000 \mathrm{~W} / \mathrm{m}^{2}$ was recorded with a corresponding PV power output of $113.8 \mathrm{KW}$ and a grid power output grid of $102 \mathrm{KW}$ in Figure 6(c).

\section{Conclusion}

With reference to Fig. 5 and Fig. 6, the effects of solar irradiance and temperature in the simulation was visible especially in Fig. 6, to attain good output power and system stability. In the case of cloud data simulation in Fig. 5, a notable disturbance or an abrupt change of solar irradiance on the input model was observed. This effect of this disturbance (due to the passing cloud) was realized at the PV and inverter output power results. Such abrupt variations in solar irradiance input to grid 
connected photovoltaic model caused fluctuations in the inverter output current in Fig. 5(d), once the penetration of solar irradiance on the photovoltaic array varies swiftly. In practice, this type of swift reduction on the photovoltaic output power affected by an abrupt decline in solar irradiance may lead to grid system instability, unplanned shutdown of the photovoltaic plant and subsequent generating generator set that are integrated with the system due to the operation of protection system settings. Also, the validity of this proposed method can provide a feasible idea about solar energy generation potential at given locations.

\section{Acknowledgement}

This work was sponsored by The Faculty of Engineering Diponegoro, Indonesia through Strategic Research Grant 2019 with contract number 3161/3/UN7.3.3/PG2019.

\section{References}

1. A. Chouder et al., Modeling and Simulation of $A$ Grid Connected PV System Based on the Evaluation of Main PV Module Parameters, Simul. Model. Pract. Theory 20(1), 46-58 (2012)

2. S. Mirhassani et al., Advances and Challenges in Grid Tied Photovoltaic Systems, Renew. Sustain. Energy Rev. 49, 121-131 (2015)

3. C. M. Whitaker et al., Utility Use of Photovoltaic System, 932-936 (1990)

4. Y.T. Tan, D.S. Kirschen, Impact on the Power System of a Large Penetration of Photovoltaic Generation, 2007 IEEE Power Eng. Soc. Gen. Meet. PES (2007)

5. Y.T. Tan, D.S. Kirschen, Impact on the Power System of A Large Penetration of Photovoltaic Generation, 2007 IEEE Power Eng. Soc. Gen. Meet. PES, 1-8 (2007).

6. R. Kimera et al., Considerations for a Sustainable Hybrid Mini-grid System: A case for Wanale village, Uganda', 25(1), 33-43 (2014)

7. H. Bellia et al., $A$ Detailed Modeling of Photovoltaic Module Using MATLAB, NRIAG J. Astron. Geophys. 3(1), 53-61 (2014).

8. www.timeanddate.com, 'Climate data.'

9. A. Durgadevi et al., Photovoltaic Modeling and Its Characteristics', 2011 Int. Conf. Emerg. Trends Electr. Comput. Technol. ICETECT 2011, 469475 (2011)

10. H. Ibrahim, N. Anani, Variations of PV Module Parameters with Irradiance and Temperature, Energy Procedia 134, 276-285 (2017)

11. A. Kumar et al., A Comprehensive Review on GridTiedSolar Photovoltaic System, J. Green Eng. 7(1), 213-254 (2017)

12. S. Narendiran, Grid Tie Inverter and MPPT - A Review, Proc. IEEE Int. Conf. Circuit, Power Comput. Technol. ICCPCT 2013, 564-567 (2013)
13. A. Nasr, A Survey of Maximum PPT Techniques of PV Systems (2016)

14. D.W. Hart, Power Electronics, 211-219

15. R. Dogga, M.K. Pathak, Recent Trends in Solar PV Inverter Topologies, Sol. Energy 183, 57-73 (2019)

16. A. Soon et al., Grid-Connected PV Generator Using Three-Phase VSC with Model Predictive Control. Springer Singapore (2019)

17. M.P. Kazmierkowski, L. Malesani, Current Control Techniques for Three-Phase VoltageSource PWM Converters: A Survey, 45(5), 691703 (1998)

18. F. Blaabjerg et al., Overview of Control and Grid Synchronization for Distributed Power Generation Systems, 53(5), 1398-1409 (2006)

19. K. Uchida, Control The Active and Reactive Powers of Three-Phase Grid-Connected Photovoltaic Inverters Using Feedback Linearization and Fuzzy Logic (2013)

20. M. Benchagra, M. Hila, Nonlinear Control of DCbus Voltage and Power for Voltage Source Inverter (2012)

21. E. Gmbh, New German Grid Codes for Connecting PV Systems to the Medium Voltage Power Grid', $1-4$ 